\title{
Incidence, Age and Gender of Subjects With the Calcium Pyrophosphate Deposition Around the Dens, and Clinical Characteristics of Patients With Crowned Dens Syndrome
}

\author{
Reo Yoshikawa ${ }^{\text {a }}$, Sumie Moriyma ${ }^{\text {a }}$, Yoshinori Masui ${ }^{a}$, Hidekatsu Yanaia, b
}

\begin{abstract}
Background: The purpose of this study was to determine the incidence, age distribution and gender of subjects with the calcifications around the dens, and to reveal the clinical, biochemical and radiological characteristics for crowned dens syndrome (CDS).

Methods: We retrospectively picked up the subjects with the calcification around the dens among patients who had undergone head and neck computed tomography (CT) between October 1, 2011 and March 31, 2012, and investigated age and gender of selected subjects. We also studied age, gender, clinical symptoms, body temperature, Creactive protein (CRP) levels, treatment and clinical course in patients who were diagnosed as having CDS.
\end{abstract}

Results: We detected 1,056 subjects who had undergone head and neck CT, and excluded subjects who had undergone repeated CT, and also excluded patients whose CT did not show odontoid process. Three hundred sixty-five subjects were eligible for the analysis. In all subjects, age in subjects with the calcifications around the dens was significantly higher than subjects without the calcifications around the dens. In subjects who were over 65 years old, age in subjects with the calcifications around the dens was also significantly higher than subjects without the calcifications around the dens. Twenty-one (5.8\%) of 365 subjects showed the calcifications around the dens. We found the calcifications around the dens in $9.6 \%$ of subjects who were over 65 years old. In the analysis of characteristics of CDS patients, we found that all patients presented neck pain, restricted neck rotation, fever, elevated CRP levels, the calcification around the dens detected by CT, and the prompt response to steroid and/or non-steroidal antiinflammatory drugs.

Conclusion: To our knowledge, our study is the first to show the

Manuscript accepted for publication September 21, 2016

a Department of Internal Medicine, National Center for Global Health and Medicine Kohnodai Hospital, Chiba, Japan

${ }^{\mathrm{b}}$ Corresponding Author: Hidekatsu Yanai, Department of Internal Medicine, National Center for Global Health and Medicine Kohnodai Hospital, 1-7-1 Kohnodai, Ichikawa, Chiba 272-0034, Japan.

Email: dyanai@hospk.ncgm.go.jp

doi: http://dx.doi.org/10.14740/jem372e frequency of the calcification around the dens in the elderly people, and also a significant association between the calcification around the dens and aging. Clinical, biochemical and radiological characteristics for CDS obtained from our study help many physicians make the diagnosis of CDS.

Keywords: Computed tomography; C-reactive protein; Crowned dens syndrome; Magnetic resonance imaging; Neck pain

\section{Introduction}

Crowned dens syndrome (CDS) is a very rare form of calcium pyrophosphate depositions and often presents with neck pain, neck stiffness and fever [1]. Clinical symptoms are due to pseudogout of the atlantoaxial junction induced by calcifications around the dens [1]. The computed tomography (CT) is the gold standard in identifying CDS, as it is able to depict the shape and site of calcification, and CT shows radiopaque densities surrounding the top and sides of the odontoid process in a crown-like distribution [1-4]. Characteristic CT findings have been reported [5-8]. The diagnosis of CDS may be based on clinical symptoms such as neck pain, neck stiffness and fever, and the calcifications surrounding the top and sides of the odontoid process which are detected by CT, and increased levels of inflammatory markers such as erythrocyte sedimentation rate and C-reactive protein (CRP) $[1,6,9,10]$.

We experienced the first patient diagnosed having CDS by clinical symptoms and the calcifications around the dens detected by CT in April 2012. The association between CDS and the calcifications around the dens remains largely unknown.

Therefore, first, we retrospectively picked up patients who showed the calcification around the dens by CT, and studied age and gender in patients with and without the calcification around the dens in the study I.

Only 52 reports about "CDS" written in English were found by Pubmed search, and most of such reports were case report. Clinical, biochemical and radiological characteristics also remain obscure. Second, we studied age, sex, symptoms, changes in CRP, treatment and clinical course in patients diagnosed as having CDS in the study II. 

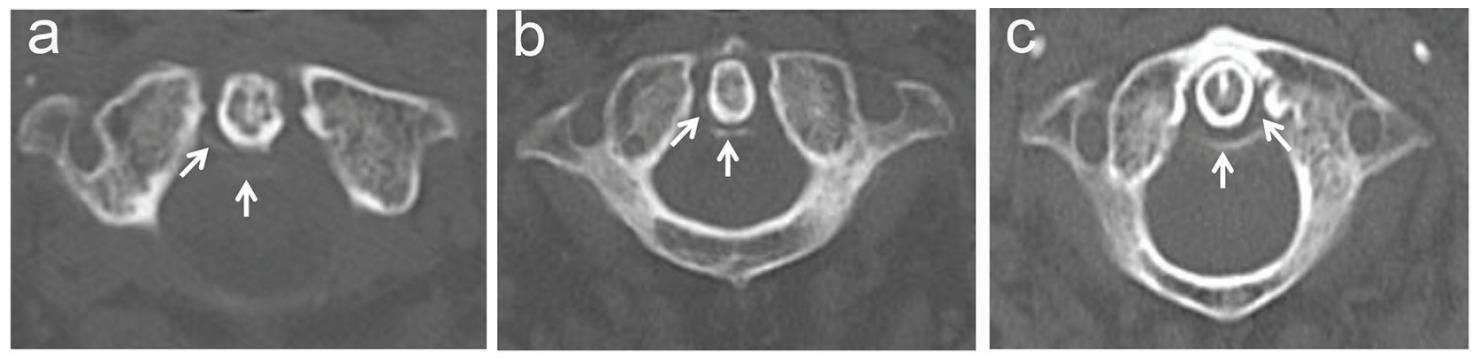

Figure 1. The calcifications around the dens by computed tomography in three patients diagnosed as having crowned dens syndrome. The axial cervical CT shows semicircular calcification (arrow-heads) at the posterolateral side of the dens. (a), (b) and (c) are CT of cases 2, 3 and 4 in Table 2.

\section{Methods}

\section{Study participants}

This study was approved by the Institutional Ethics Committee in National Center for Global Health and Medicine (NCGMG-002053-00), and was also performed in accordance with the Declaration of Helsinki. We retrospectively picked up the subjects with the calcification around the dens among patients who had undergone head and neck CT between October 1, 2011 and March 31, 2012 in the study I. We also studied clinical, biochemical and radiological data of patients diagnosed as having CDS by medical chart, in the study II.

\section{Data collection and statistical analysis}

We collected data about age and gender in the study I, and obtained data including age, sex, body temperature, CRP, CT findings, treatment and clinical course in the study II.

Comparisons of age and sex between patients with and without the calcifications around the dens by CT were performed by Mann-Whitney U test and Chi-square test, respectively. $\mathrm{P}<0.05$ was considered to be statistically significant.

\section{Results}

\section{Study I}

Figure 1 shows the calcifications around the dens by CT in three patients diagnosed as having CDS. The axial cervical CT shows semicircular calcification (arrow-heads) at the posterolateral side of the dens.

The strategy to pick up subjects and results was shown in Figure 2. We detected 1,056 subjects who had undergone head and neck $\mathrm{CT}$, and excluded subjects who had undergone repeated CT, and also excluded patients whose CT did not show odontoid process. Three hundred sixty-five subjects were eligible for the analysis in the study I. In all subjects, age in subjects with the calcifications around the dens was significantly higher than subjects without the calcifications around the dens

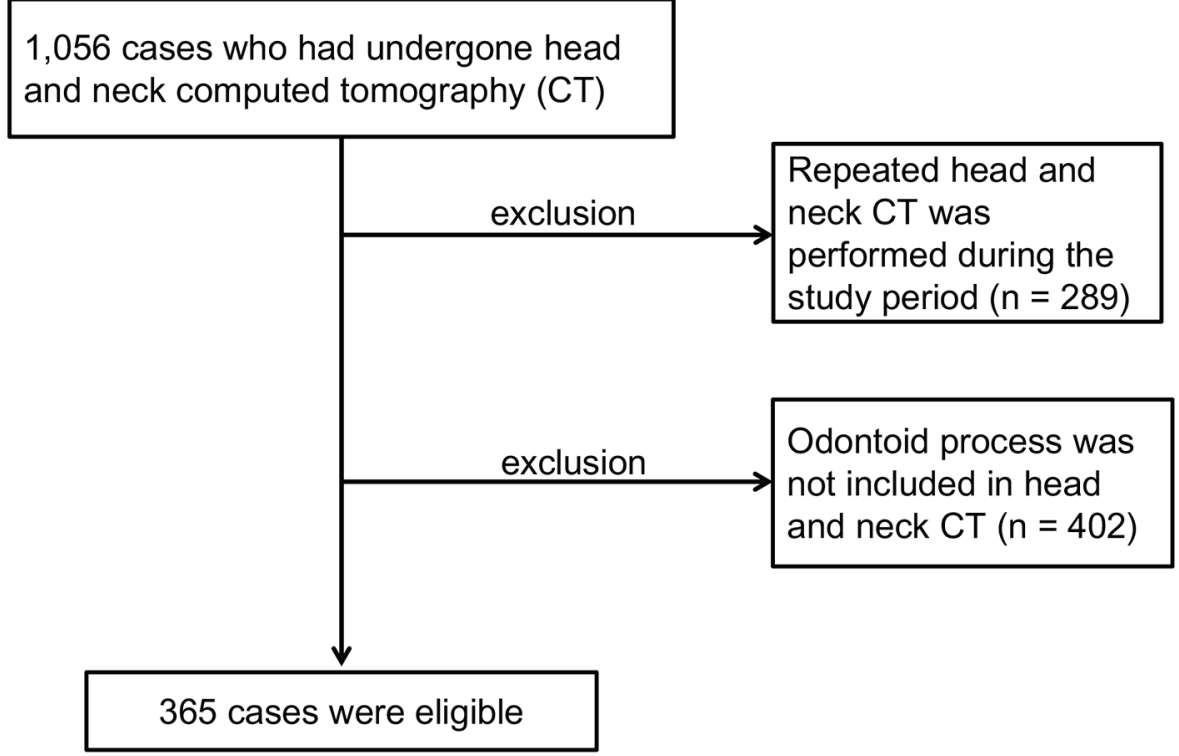

Figure 2. The strategy to pick up subjects and results. 


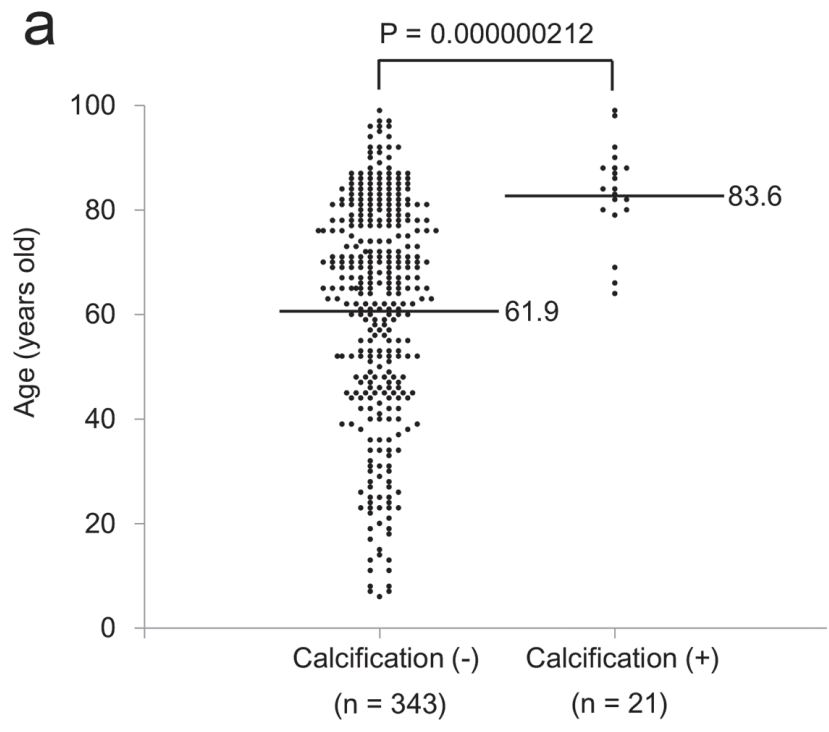

b

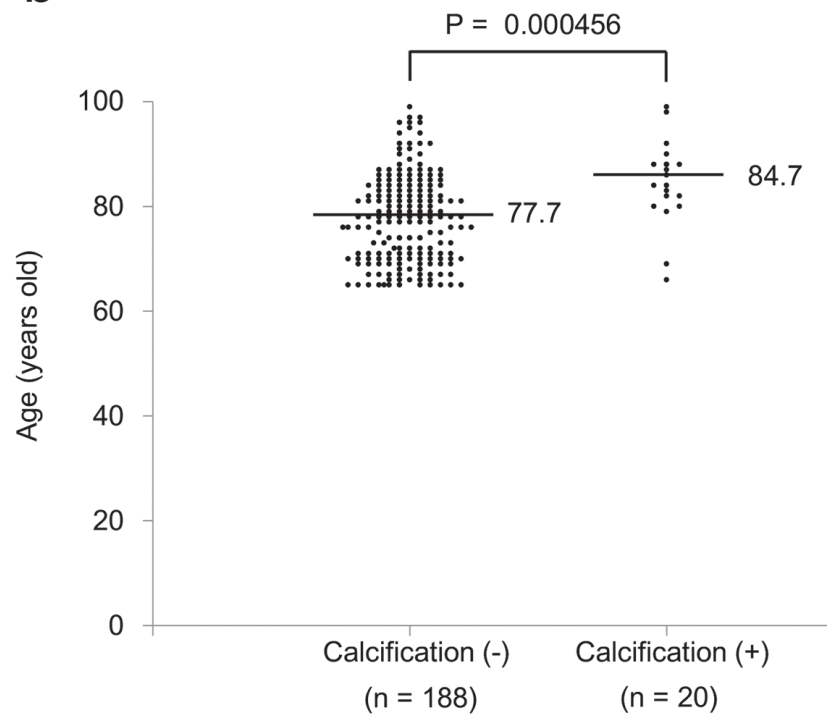

Figure 3. Age distribution and mean age in subjects with and without the calcification around the dens in all subjects (a) and subjects who were over 65 years old (b). Values on the side of horizontal bars indicate mean age.

(Fig. 3a). In subjects who were over 65 years old, age in subjects with the calcifications around the dens was also significantly higher than subjects without the calcifications around the dens (Fig. 3b).

Age, gender and frequency of the calcifications around the dens in all eligible subjects, and frequency of calcifications around the dens in subjects who were over 65 years old, and gender in subjects with calcifications around the dens are shown in Table 1. Approximately $6 \%$ of 365 subjects showed the calcifications around the dens. We found the calcifications around the dens in about $10 \%$ of subjects who were over 65 years old.
Table 1. Age, Gender and Frequency of Calcifications Around the Dens in All Eligible Subjects, and Frequency of Calcifications Around the Dens in Subjects Who Were Over 65 Years Old, and Gender in Subjects With Calcifications Around the Dens

\begin{tabular}{|c|c|}
\hline \multicolumn{2}{|c|}{ All eligible subjects $(n=365)$} \\
\hline Range of age (years) & $6-99$ \\
\hline Male/female (n) & $169 / 196$ \\
\hline \multicolumn{2}{|c|}{ Calcification around the dens } \\
\hline Absence, n (\%) & $343(94.2 \%)$ \\
\hline Presence, $\mathrm{n}(\%)$ & $21(5.8 \%)$ \\
\hline \multicolumn{2}{|c|}{ Subjects who were over 65 years old $(n=208)$} \\
\hline \multicolumn{2}{|c|}{ Calcification around the dens } \\
\hline Absence, $\mathrm{n}(\%)$ & $188(90.4 \%)$ \\
\hline Presence, $\mathrm{n}(\%)$ & $20(9.6 \%)$ \\
\hline \multicolumn{2}{|c|}{ Subjects with calcification around the dense $(n=21)$} \\
\hline Male/female (n) & $6 / 15$ \\
\hline
\end{tabular}

The positive rate of the calcifications around the dens in females $(7.7 \%)$ tended to be higher than those in males $(3.6 \%)$ $(\mathrm{P}=0.093)$.

\section{Study II}

Age, gender, clinical symptoms, body temperature, changes in CRP levels, treatment and clinical course in patients diagnosed as having CDS are shown in Table 2. All patients presented neck pain, restricted neck rotation, fever and elevated CRP levels. Symptoms and CRP in cases 1 - 9 were promptly ameliorated by steroid and/or non-steroidal anti-inflammatory drugs (NSAIDs).

However, symptoms and CRP were deteriorated by NSAID in case 10, and blood culture showed the growth of Staphylococcus aureus. The CT in case 10 showed the calcification around the dens as well as cases 1 - 9 (Fig. 4). However, magnetic resonance imaging (MRI) revealed pyogenic spondylodiscitis in $\mathrm{C} 5$ and $\mathrm{C} 6$ vertebrae and the $\mathrm{C} 5-\mathrm{C} 6$ disc (Fig. 5).

\section{Discussion}

In the study I, we studied the association between age and the calcifications around the dens, and found that age in subjects with the calcifications around the dens was significantly higher than subjects without the calcifications. The mean age of patients with the calcification around the dens was 83.6 years old. Further, we found that approximately $10 \%$ of subjects who were over 65 years old showed the calcifications around the dens. Further, the mean age of subjects diagnosed having CDS was 83.1 years old, and the range of age was 69 - 92 years old. Present study indicated a significant association of the calcifications around the dens and CDS with old age. 
Table 2. Age, Sex, Symptoms, Body Temperature, Changes in CRP Levels, Treatment and Clinical Course in Patients Diagnosed as Having Crowned Dens Syndrome

\begin{tabular}{|c|c|c|c|c|c|c|}
\hline Cases & $\begin{array}{l}\text { Age/ } \\
\text { sex }\end{array}$ & Symptoms & BT $\left({ }^{\circ} \mathrm{C}\right)$ & $\begin{array}{l}\text { Changes in CRP } \\
\text { levels }(\mathrm{mg} / \mathrm{dL})\end{array}$ & Treatment & Clinical course \\
\hline 1 & $85 / \mathrm{F}$ & $\begin{array}{l}\text { Neck pain, restricted } \\
\text { neck rotation }\end{array}$ & 37.9 & $\begin{array}{l}0.57 \rightarrow 1.57(\text { day } \\
3) \rightarrow 0.22(\text { day } 7)\end{array}$ & Celecoxib $400 \mathrm{mg} / \mathrm{day}$ & $\begin{array}{l}\text { Symptoms and fever were promptly } \\
\text { ameliorated on day } 2\end{array}$ \\
\hline 3 & $69 / \mathrm{M}$ & $\begin{array}{l}\text { Neck pain, restricted } \\
\text { neck rotation }\end{array}$ & 37.6 & $\begin{array}{l}4.63 \rightarrow 0.91(\text { day } \\
4) \rightarrow 0.35(\text { day } 6)\end{array}$ & PSL 15 mg/day & $\begin{array}{l}\text { Symptoms and fever were promptly } \\
\text { ameliorated on day } 2\end{array}$ \\
\hline 5 & $85 / \mathrm{F}$ & $\begin{array}{l}\text { Neck pain, restricted } \\
\text { neck rotation }\end{array}$ & 38.4 & $\begin{array}{l}14.33 \rightarrow 5.88 \text { (day } \\
5) \rightarrow 4.21(\text { day } 7)\end{array}$ & No medication & $\begin{array}{l}\text { Symptoms were promptly ameliorated } \\
\text { on day } 1 \text {, and fever was gone on day } 2\end{array}$ \\
\hline 6 & $87 / \mathrm{F}$ & $\begin{array}{l}\text { Neck pain, restricted } \\
\text { neck rotation }\end{array}$ & 38.1 & $\begin{array}{l}5.99 \rightarrow 1.38 \text { (day } \\
4) \rightarrow 0.37(\text { day } 7)\end{array}$ & Celecoxib 400 mg/day & $\begin{array}{l}\text { Symptoms were promptly ameliorated } \\
\text { on day } 1 \text {, and fever was gone on day } 2\end{array}$ \\
\hline 9 & $82 / \mathrm{M}$ & $\begin{array}{l}\text { Neck pain, restricted neck } \\
\text { rotation, polyarthralgia }\end{array}$ & 39.2 & $\begin{array}{l}12.45 \rightarrow 7.42(\text { day } \\
2) \rightarrow 0.52(\text { day } 4)\end{array}$ & PSL $30 \mathrm{mg}$ & $\begin{array}{l}\text { Symptoms were promptly ameliorated } \\
\text { on day } 1 \text {, and fever was gone on day } 2\end{array}$ \\
\hline 10 & $79 / \mathrm{F}$ & $\begin{array}{l}\text { Neck pain, restricted } \\
\text { neck rotation }\end{array}$ & 38.3 & $\begin{array}{l}14.30 \rightarrow 16.41 \\
(\text { day } 1)\end{array}$ & Celecoxib 400 mg/day & $\begin{array}{l}\text { Any amelioration in symptoms and } \\
\text { fever were not observed on day } 2\end{array}$ \\
\hline
\end{tabular}

BT: body temperature; CRP: C-reactive protein; F: female; M: male; PSL: prednisolone.
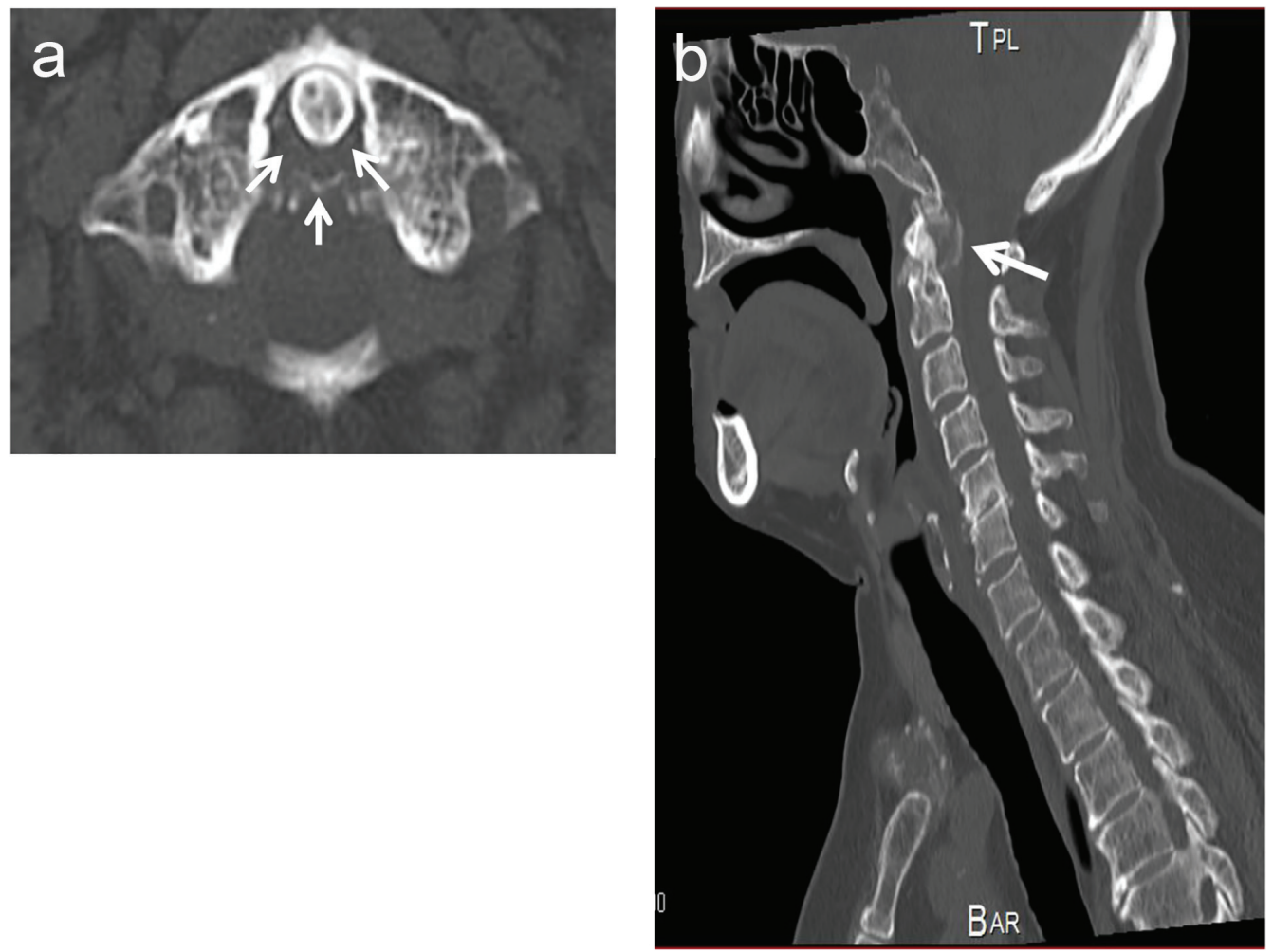

Figure 4. The axial cervical computed tomography (CT) image (a) and the sagittal CT image (b) of case 10 in Table 2. CT showed the calcification (arrow-heads) at the posterolateral side of the dens. 


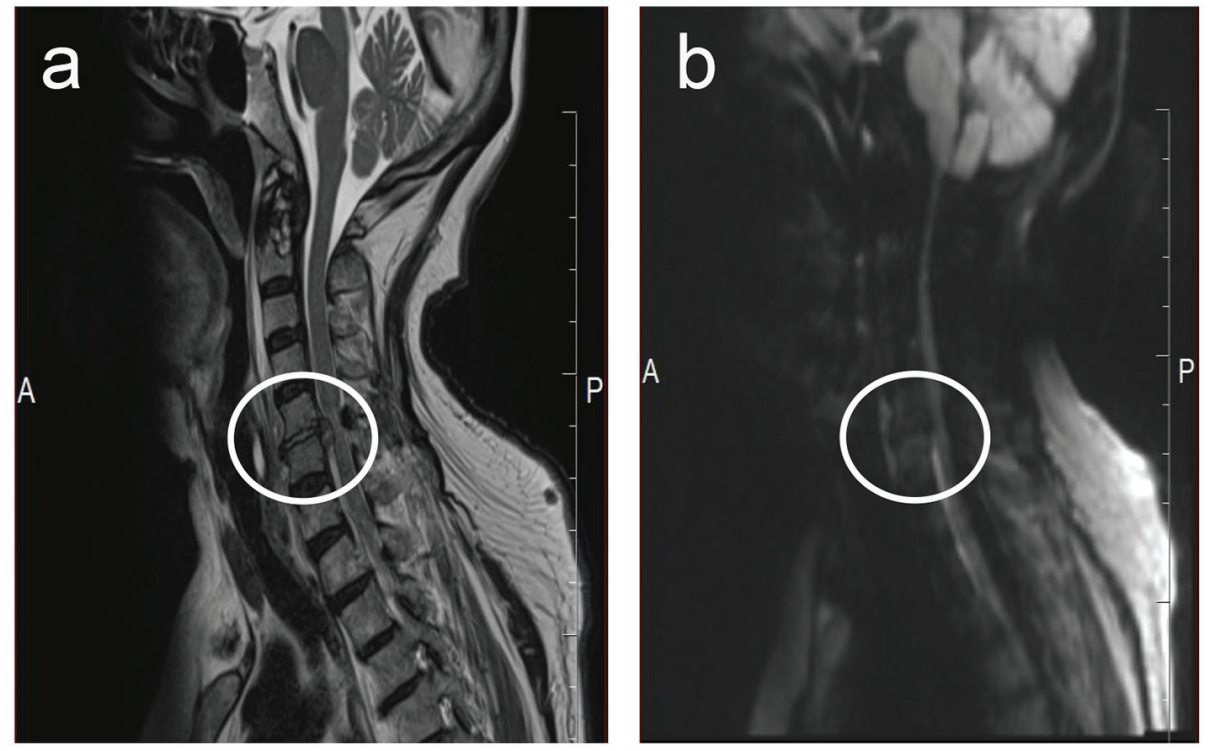

Figure 5. Magnetic resonance imaging of case 10 in Table 2. (a) and (b) are T2-weighted image and diffusion-weighted image, respectively. High-intensity area (area inside the circle) was observed in both T2-weighted image and diffusion-weighted image, suggesting the existence of pyogenic spondylodiscitis in C5 and C6 vertebrae and the C5-C6 disc.

According to our Pubmed search (reports written in English), the mean age in patients with CDS was 78.1 years old (11 males and 11 females), supporting a significant association between CDS and old age [2, 4, 5, 7, 8, 11-23].

The positive rate of the calcifications around the dens in females was about twice as high as those in males in study I, suggesting a female predominance in the calcifications around the dens. The previous study reported that the maleto-female ratio was 0.6 in $40 \mathrm{CDS}$ patients [10]. GodfrinValnet et al reported 18 cases of CDS and they also suggested that CDS affects women over 60 years old [24]. However, nine subjects with CDS in our study II included five females and four males, which did not agree with the previous two studies $[10,24]$. Further, according to case reports accumulated by our Pubmed search, 11 of 22 cases with CDS were women, challenging a female predominance in $\operatorname{CDS}[2,4$, $5,7,8,10-24]$. To confirm a female predominance in CDS, further studies, preferably with a greater number of CDS subjects, are needed.

Clinical, biochemical and radiological characteristics for CDS obtained from our study II are shown in Table 3. All CDS patients (cases 1 - 9) and also case 10 showed neck pain, re-

Table 3. Clinical, Biochemical and Radiological Characteristics for Crowned Dens Syndrome

\begin{tabular}{ll}
\hline 1 & Elderly people \\
2 & Neck pain, restricted neck rotation and fever \\
3 & Elevated serum CRP levels \\
4 & The calcification around the dens detected by CT \\
5 & The prompt response to steroid and/or NSAIDs \\
\hline
\end{tabular}

CRP: C-reactive protein; CT: computed tomography; NSAIDs: nonsteroidal anti-inflammatory drugs. stricted neck rotation, fever and elevated CRP levels and the calcification around the dens detected by CT (Table 2). Further, the prompt response to steroid and/or NSAIDs helped us make the diagnosis of CDS. The patient who did not show the prompt response to NSAID was finally diagnosed as having pyogenic spondylodiscitis due to Staphylococcus aureus by MRI and blood culture. This patient is very suggestive. First, the prompt response to steroid and/or NSAIDs is a very important tool to differentiate CDS from other diseases. Second, CT cannot detect pyogenic spondylodiscitis, which can be found by MRI. CT is the gold standard in identifying CDS, as it is able to depict the shape and site of calcification [1-4]. If we diagnosed patients as having CDS and the prompt response to steroid and/or NSAIDs was not obtained, we should perform MRI to differentiate other diseases such as infections or neurological emergencies.

We have to mention the limitation of our study. First, the study I is a cross-sectional and retrospective study which did detect the calcification around the dens but did not detect the development of CDS. Briefly, in the study I, it is unknown whether the subjects with the calcifications around the dens developed CDS or not. Second, the number of subjects in both study I and II was small.

\section{Conclusion}

To our knowledge, our study is the first to show the frequency of the calcification around the dens in the elderly people, and also a significant association between the calcification around the dens and aging. CDS has been reported to be misdiagnosed and under-recognized as a cause of acute neck pain and fever of unknown origin $[25,26]$. Clinical, biochemical and radiological characteristics for CDS obtained from our study may 
help many physicians make the diagnosis of CDS.

\section{Author Contributions}

RY and HY designed the research. RY, YM and SM collected data. RY and HY analyzed data, and wrote the paper. All authors read and approved the final paper.

\section{Conflicts of Interest}

The authors declare that they have no conflicts of interest concerning this article.

\section{Funding}

This work was supported in part by Grants-in-Aid for Research from the National Center for Global Health and Medicine (26-112).

\section{References}

1. Bouvet JP, le Parc JM, Michalski B, Benlahrache C, Auquier L. Acute neck pain due to calcifications surrounding the odontoid process: the crowned dens syndrome. Arthritis Rheum. 1985;28(12):1417-1420.

2. Wu DW, Reginato AJ, Torriani M, Robinson DR, Reginato AM. The crowned dens syndrome as a cause of neck pain: report of two new cases and review of the literature. Arthritis Rheum. 2005;53(1):133-137.

3. Scutellari PN, Galeotti R, Leprotti S, Ridolfi M, Franciosi $\mathrm{R}$, Antinolfi G. The crowned dens syndrome. Evaluation with CT imaging. Radiol Med. 2007;112(2):195-207.

4. Zhang H, Jin D, Sun E. The early and late stages of crowned dens syndrome: two case reports. Spine J. 2015;15(10):e65-68.

5. Morita T, Tanimoto T, Kaji S, Fukutake T. Poststroke crowned dens syndrome. Spine J. 2013;13(9):1161-1162.

6. Salaffi F, Carotti M, Guglielmi G, Passarini G, Grassi W. The crowned dens syndrome as a cause of neck pain: clinical and computed tomography study in patients with calcium pyrophosphate dihydrate deposition disease. Clin Exp Rheumatol. 2008;26(6):1040-1046.

7. Inokuchi $\mathrm{R}$, Ohshima $\mathrm{K}$, Yamamoto $\mathrm{M}$, Fukuda $\mathrm{T}$, Nakamura K. Crowned dens syndrome. Spine J. 2015;15(6):1499-1500.

8. Oka A, Okazaki K, Takeno A, Kumanomido S, Kusunoki R, Sato S, Ishihara S, et al. Crowned Dens Syndrome: Report of Three Cases and a Review of the Literature. J Emerg Med. 2015;49(1):e9-e13.

9. Ferrone C, Andracco R, Cimmino MA. Calcium pyrophosphate deposition disease: clinical manifestations. Reumatismo. 2011;63(4):246-252.
10. Goto S, Umehara J, Aizawa T, Kokubun S. Crowned Dens syndrome. J Bone Joint Surg Am. 2007;89(12):27322736.

11. Koda R, Tsuchida Y, Yoshizawa K, Suzuki K, Kasai A, Takeda T, Kazama JJ, et al. Crowned Dens Syndrome as an Initial Manifestation of Crystalline Deposition Disease. Intern Med. 2015;54(18):2405-2408.

12. Tamura T, Suzuki M, Hori S. Crowned dens syndrome. Intern Med. 2015;54(5):545.

13. Tagami S, Inokuchi R, Awaji K, Maehara H, Yamaguchi Y, Nakajima S. Crowned dens syndrome and interspinous ligament inflammation due to calcium pyrophosphate deposition in an elderly man. Spine J. 2016;16(7):e453454.

14. Monet A, Massonnat R, Merino B, Riviere A, Richez C. Crowned dens syndrome diagnosed on (1)(8)F-FDG PET/CT. Clin Nucl Med. 2014;39(12):1041-1042.

15. Viana M, Sainaghi PP, Stecco A, Mortara F, Sprenger T, Goadsby PJ. Headache in a patient with crowned dens: report of a new case. Headache. 2014;54(7):1211-1216.

16. Kuriyama A. Crowned dens syndrome. CMAJ. 2014;186(4):293.

17. Garcia-Gonzalez E, Baldi C, Guidelli GM, Selvi E. Crowned dens syndrome and cervical interspinous bursitis mimicking acute meningitis. J Clin Rheumatol. 2013;19(6):357-358.

18. Oda Y, Ooi S, Urushidani Y, Endo A. Crowned dens syndrome. Intern Med. 2012;51(2):231.

19. Ali S, Hoch M, Dadhania V, Khurana JS. CPPD crowned dens syndrome with clivus destruction: a case report. J Radiol Case Rep. 2011;5(8):30-37.

20. Ishikawa K, Furuya T, Noda K, Okuma Y. Crowned dens syndrome mimicking meningitis. Intern Med. 2010;49(18):2023.

21. Sato T, Hagiwara K, Sasaki M, Matsuno H, Akiyama O. Crowned dens syndrome. Intern Med. 2005;44(2):160.

22. Sato Y, Yasuda T, Konno S, Kuwayama A, Komatsu K. Pseudogout showing meningoencephalitic symptoms: crowned dens syndrome. Intern Med. 2004;43(9):865868.

23. Mula M, Bordin G, Naldi P, Gaviani P, Leone M, Monaco F. Crowned dens syndrome in an elderly man. Neurology. 2001;56(2):275

24. Godfrin-Valnet M, Godfrin G, Godard J, Prati C, Toussirot E, Michel F, Wendling D. Eighteen cases of crowned dens syndrome: Presentation and diagnosis. Neurochirurgie. 2013;59(3):115-120.

25. Aouba A, Vuillemin-Bodaghi V, Mutschler C, De Bandt M. Crowned dens syndrome misdiagnosed as polymyalgia rheumatica, giant cell arteritis, meningitis or spondylitis: an analysis of eight cases. Rheumatology (Oxford). 2004;43(12):1508-1512.

26. Sekijima Y, Yoshida T, Ikeda S. CPPD crystal deposition disease of the cervical spine: a common cause of acute neck pain encountered in the neurology department. $\mathbf{J}$ Neurol Sci. 2010;296(1-2):79-82. 